\section{Australia's CSIRO takes the flak from Senate committee}

Sydney. The management and board of the Commonwealth Scientific and Industrial Research Organisation (CSIRO), Australia's leading research organization and its largest employer of scientists, have come in for some harsh criticism from a parliamentary committee.

A report released last week by the Economics Reference Committee of the Australian Senate describes the board of CSIRO as "ineffectual". On the basis of hearings held in Canberra, the federal capital, over the past few months, the committee claims that the board allowed the organization to become over-managed, with an "archaic, hierarchical, top-heavy management system", to the point where research became badly affected.

The committee's report also says that the board had neglected the employment conditions and morale of its staff and taken an "intrusive" role in matters of administration that should have been left to the organization's chief executive officer (CEO), John Stocker, and his executive committee.

At the same time, Stocker, who is a member of the board, is personally criticized for making a "tokenist response" to management problems raised by the Senate committee by simply pointing to the organization's adoption of the management discipline of Total Quality Management (TQM). Earlier this year, Stocker announced that he would not be seeking reappointment for another five year term as CEO, when his present term expires in March 1995.

The committee's inquiry was initiated by complaints from Australia's strong but drought-affected - rural sector about a decision by the research agency to cut back funds for rural research. Announced earlier this year, the cuts are partly the result of changes in the organization's priorities as well as efforts to reduce the CSIRO's A \$126million budget by 13 per cent (see Nature 369, 347; 1994).

The CSIRO is not obliged to act on any of the committee's recommendations. But the report is likely to have a strong influence on the government's deliberations over the state-owned organization's future.

As well as declaring that the cuts in funding for rural research should be reversed, the committee recommends that CSIRO should improve its efforts to commercialize research, reassess the effect of external funding policies on fundamental research and improve communications with the public.

But the report's main criticisms concerned the management of CSIRO in general and its institute structure in particular, which the committee recommended should be abolished or modified.

CSIRO's main operating units are known as divisions which, in 1986, were grouped into six institutes of broadly similar research areas, such as the Institute of Animal Production and Processing, based in Sydney.

The committee had received a large number of submissions from individual scientists, which all strongly criticized the institutes as having no particular function. Rather than adding value to the research or commercialization process, the report said, institutes had become involved in matters of accountability and review, generating "a vast amount of paperwork without clear and worthwhile objectives".

The CSIRO has so far said little in response to this report. But an internal commit-

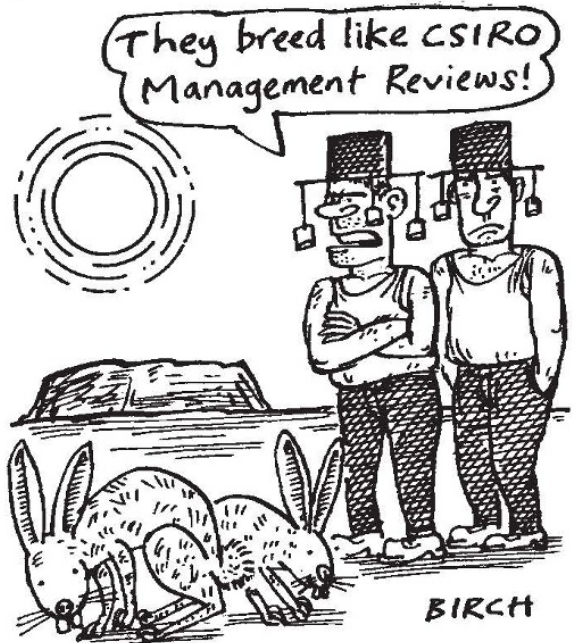

tee is now examining the organization's structure, and will report in February.

But the Senate committee's report also criticizes the management review committee, chaired by the chairman of the CSIRO, Adrienne Clarke. It found the terms of reference of the review to be "very general" and "so unfocused as to be almost incomprehensible". It points out that there had already been a series of management reviews that had led, not to any change in structure, but to a proliferation of corporate managers and administrators.

Among other points made by the report, the Senate committee notes that scientists had become frustrated by endless reviews of CSIRO (one scientist complained his area of research was reviewed four times in 12 months); that administrative staff appear to cost the same per person as research staff despite not having research programme costs; and that both science and management appeared to have suffered through the practice of promoting scientists to management positions.

\section{Biodiversity treaty nations to study biosafety protocol}

Nassau, Bahamas. The signatory states to the United Nations (UN) Convention on Biological Diversity formally agreed last week to study the need for a global biosafety protocol in the coming year.

At the conclusion of the first meeting of the 'conference of parties', held in Nassau in the Bahamas over the previous two weeks, they also agreed to examine the relationship between questions of access to genetic resources, technology transfer to developing nations and intellectual property rights.

A study commissioned during the preceding year of preparatory meetings had pointed out the need for a biosafety protocol to regulate the production and release of genetically modified organisms. Many delegates and representatives of non-government organizations (NGOs) were therefore disappointed by the insistence of several developed countries on reopening this question in the coming year. They would have preferred future meetings to consider the actual wording of such a protocol.

The United Kingdom and the Netherlands had proposed a set of interim guidelines on biosafety that have been formally adopted as a basis for future guidelines by the United Nations Environment Programme. But the proposal was criticized on the grounds that, since many developing countries have inadequate or non-existent biosafety laws, such guidelines would be voluntary - and hence easily ignored.

During the pre-conference negotiations, developing countries pushed for action on the issue of equitable access to, and development of, genetic resources of potential value to major industries such as pharmaceutical or agrochemicals - an issue raised explicitly in the Biodiversity Convention.

They argued that access to these resources should imply a quid pro quo that might include exchange of technology or other immediate benefits, as well as the sharing of royalties or inventorship. This could bring new economic incentives for the conservation and sustainable use of biological diversity.

One item that has therefore been adopted as part of the 1995 work programme for the parties to the convention is a study of intellectual property rights.

The 1995 programme also includes the need to consider national strategies to promote biodiversity conservation, which may eventually require all parties to formulate programmes of action. Parties to the convention will also consider the conservation of coastal and marine biodiversity.

But although forests are home to an estimated 60 per cent of the world's species, sustainable forestry is not included.

Daniel Putterman 